\title{
Nanocrystalline Cellulose as Effect Pigment in Clear Coatings for Wood
}

\author{
Mirela Simona Vlad-Cristea, ${ }^{1}$ Véronic Landry, ${ }^{1}$ \\ Pierre Blanchet, ${ }^{2}$ and Claudiane Ouellet-Plamondon ${ }^{3}$ \\ ${ }^{1}$ FPInnovations, Secondary Wood Products Manufacturing, Québec, QC, Canada G1P 4R4 \\ ${ }^{2}$ Wood and Forest Sciences Department, Université Laval, Québec, QC, Canada G1V 0A6 \\ ${ }^{3}$ Institute for Construction and Infrastructure Management, ETH Zurich, 8092 Zurich, Switzerland
}

Correspondence should be addressed to Mirela Simona Vlad-Cristea; mirela.vlad@fpinnovations.ca

Received 3 July 2013; Accepted 26 July 2013

Academic Editors: P. Kumbhakar, C. Li, and Z.-M. Liao

Copyright (C) 2013 Mirela Simona Vlad-Cristea et al. This is an open access article distributed under the Creative Commons Attribution License, which permits unrestricted use, distribution, and reproduction in any medium, provided the original work is properly cited.

\begin{abstract}
Nanocrystalline cellulose (CNC) is a renewable material with high potential in many applications. Due to its unique self-assembly and optical properties, CNC tends to behave as an iridescent pigment. The aim of this research was to explore the potential of $\mathrm{CNC}$ as an effect pigment in wood coatings. CNC-based coatings were developed from an aqueous CNC solution, a UV-curable water-based clear coating formulation, several colorants, and specialized additives. In this paper, the morphology of the resulting CNC films was investigated through circular dichroism and optical microscopy under polarized light. The effect of the CNC surface charge changes was monitored through zeta potential measurements. Color changes, or travel, and flop index were used to assess the iridescent effect of the coatings containing CNC. The experimental wood coatings contained CNC showed that the enhancement of the iridescent effect depends on the distribution and alignment of the $\mathrm{CNC}$ rod-like particles in order to generate the right pitch in the helical structure and their interaction with the polymer matrix as well with the additives. In conclusion, CNC could be successfully used as effect pigment in finishing systems, which can enhance the attractiveness and bring out the special grain of various types of wood.
\end{abstract}

\section{Introduction}

Nanocrystalline cellulose (CNC) is a renewable material with high potential in many applications. CNC is generally produced by controlled acid hydrolysis from bleached wood pulp $[1,2]$ and its production does not pose a significant threat to the environment. The resulting CNC rod-like particles are $100-200 \mathrm{~nm}$ in length with cross-sections of 3-5 $\mathrm{nm}$ (for an aspect ratio of 30-67) [3].

Favier et al. [4] used CNC as a reinforcing agent in polymer composites. Cao et al. [5] prepared water-based polyurethane films with CNC from flax. With the addition of $10 \%$ of $\mathrm{CNC}(\mathrm{w} / \mathrm{w})$, they obtained modulus in flexure values 16 times greater than for regular polyurethane films without CNC. CNC could therefore be of interest to the paint and coatings industries. New high value-added products based on $\mathrm{CNC}$ can be developed in this competitive sector.
Gray and coworkers discovered that a unique selfassembled ordered liquid crystal phase was formed when the cellulose crystallites were sufficiently short and uniform (always less than $100 \mathrm{~nm}$ ) and had a high degree of sulfates esterified onto the surface $[3,6]$. When the aqueous CNC suspension reached a critical concentration (called cholesteric phase), chiral nematic ordered structures formed and arranged themselves in a staircase-like helical superstructure along one axis (called the director) [7]. The thickness of the layer structure up to a complete turn of the director is the pitch $(P)$ of the helix. The wavelength of the reflected light $(\lambda)$ depends on the pitch $(P)$ of the stacked planes of CNC and the average refractive index $(n)$ of the CNC film, according to the equation established by de Vries [8]:

$$
\lambda=n P .
$$


Due to its unique self-assembly and optical properties, CNC tends to behave as an interference pigment, showing significant color changes, or travel, as the viewing angle changes. Accordingly, Revol et al. [9] extended (1) to

$$
\lambda=n P \sin \theta,
$$

where $\lambda$ is the wavelength of the reflected light, $n$ is average refractive index, $P$ is the pitch of the stacked planes of CNC, and $\theta$ is the angle between the normal to the surface and the viewing angle.

CNC films having the optical properties of a chiral nematic liquid crystal could be prepared by simple casting from aqueous suspensions. Circular dichroism (CD) can be used to measure the difference in apparent absorption of left-handed $(\mathrm{AL})$ and right-handed $(\mathrm{AR})$ circularly polarized light:

$$
\mathrm{CD}=\mathrm{AL}-\mathrm{AR}
$$

A positive CD signal indicates that the chiral nematic structure predominantly reflects left-handed circularly polarized light [10], while a negative $C D$ signal indicates a righthanded helix [11]. The chiral nematic structure of CNC films produces high rotatory power and reflects left-handed circularly polarized light in a narrow wavelength band [9].

Previous studies had established that, by adding an electrolyte or providing ultrasonic energy to the $\mathrm{CNC}$ suspension, one could control the reflection wavelength of iridescent solid CNC films $[12,13]$. However, $100 \%$ CNC films are very brittle and difficult to handle, which limits their suitability for commercial applications. Zou et al. [14] prepared flexible CNC films incorporating polyvinyl alcohol (PVOH) and styrenebutadiene rubber (SBR) latex that retained the iridescent effect. Concentrations of 10-15\% PVOH yielded the highest flexibility and best optical properties, while a concentration of $15 \%$ SBR latex yielded the best tensile strength and optical properties in the CNC-SBR latex films.

Cholesteric liquid crystals can be used as polymerized platelets (polysiloxanes, commercially available in thicknesses over $4 \mu \mathrm{m}$ ) or directly as fluid phases where the liquid crystals orient themselves into their supramolecular structure when applied onto a substrate. Unfortunately, the use of cholesteric effect pigments based on liquid-crystal polymers is restricted by their insufficient stability and workability in a number of applications [15].

In recent years, the possibility to use special effect pigment in wood coatings for furniture or flooring has attracted the attention of architects and designers. Effect pigments can enhance the attractiveness of wood surfaces. For example, they are increasingly used in kitchen furniture coatings having a silky effect, which cannot be produced with conventional pigments [15]. Reproducing the iridescent effect of the natural periodic optical nanostructure remains a technological challenge [16].

The aim of this research was to explore the potential of $\mathrm{CNC}$ as an interference pigment in wood coatings. CNCbased special-effect coatings were developed from an aqueous CNC solution, a UV-curable water-based clear coating formulation, several colorants, and additives. The colorants used in this study are already widely used in the paints and coatings industry. In this paper we investigated the morphology of the resulting CNC films. More specifically, we considered the effect of these additions on the chiral nematic phase at a macroscopic level using circular dichroism and optical microscopy under polarized light. The effect of the $\mathrm{CNC}$ surface charge variation (hence colloidal stability) was monitored through measurements of the zeta potential of the suspension.

Color travel and flop index were used to assess the iridescent effect of the free films and wood coatings containing CNC. This characterization approach is often used by industries that consume effect pigments.

\section{Materials and Methods}

2.1. Materials. The $\mathrm{CNC}$ aqueous suspension $(5.3 \% \mathrm{w} / \mathrm{w})$ used in this study was provided by FPInnovations (PointeClaire, Quebec, Canada). The CNC was prepared at the FPInnovations pilot plant by acid hydrolysis of a commercial bleached softwood kraft pulp. The $\mathrm{pH}$ of the suspensions was adjusted to 7 for improved compatibility with the coating formulations. According to Beck et al. [17], the CNC employed was derived from cellulose bearing sulfate ester groups associated with alkali metal cations.

Prior to use, $500 \mathrm{~mL}$ batches of the aqueous suspension were homogenized for 10 minutes in an ultrasonic homogenizer (Cole Parmer $750 \mathrm{~W}$, Illinois, USA) set at $40 \%$ of maximum power.

A water-based UV-curable varnish was prepared in accordance with formulas listed in Table 1. The list of industrial colorants under study is shown in Table 2, with the list of additives used to improve CNC orientation in Table 3.

Boards of sugar maple, that were sawn in tangential sections, were planned and conditioned in a climate controlled room at a temperature of $20^{\circ} \mathrm{C}$ and a relative humidity of $50 \%$ until they reached a constant mass. Prior to cutting the wood in samples, the boards were sanded in sequence with 120,150 , and 180 grit papers. The dimensions of the samples used to applying the prepared formulations were $101.6 \mathrm{~mm} \times$ $101.6 \mathrm{~mm} \times 19 \mathrm{~mm}(L \times T \times R)$.

2.2. Methods. The formulations shown in Table 4 were prepared with a high speed mixer (Ragogna, Canada Ltd. Company) at $1000 \mathrm{rpm}$ for 15 minutes. For film casting, $25 \mathrm{~g}$ of a given formulation was poured into $100 \times 15 \mathrm{~mm}$ petri dishes and dried for 24 hours in air at $20^{\circ} \mathrm{C}$. The thicknesses of the prepared films were between 80 , and $90 \mu \mathrm{m}$. The free films were subsequently analyzed by optical microscopy and circular dichroism. Application of the formulations onto wood specimens was achieved through pulverization with a spray gun. Five samples of wood were used for each finishing system. In all finishing systems, the first coat used a varnish without $\mathrm{CNC}$, the wet film thickness being 75-80 $\mu \mathrm{m}$. Once UV cured, the first coat was sanded with a 320 grit sandpaper. Two coats of CNC-based varnish were then applied. The wet film thickness of these latter coats was set at $380 \mu \mathrm{m}$ following trials at 102,305 , and $610 \mu \mathrm{m}$. The finishing system used as 
TABLE 1: UV-curable waterbased varnish formulation.

\begin{tabular}{lccc}
\hline Additive & Commercial name & Role & $\%$ wt. \\
\hline Urhetane acrylate dispersion & Bayhydrol UV 2282 (Bayer) & Resin & 92.14 \\
Polyetherdimethylsiloxane copolymer & Byk 025 (Byk-Chemie) & Defoamer & 0.5 \\
Polyethersiloxane copolymer & Byk 348 (Byk-Chemie) & Surfactant & 0.46 \\
Bisacylphospine oxide & Irgacure 819DW (BASF) & Photoinitiator & 0.92 \\
Polyurethane & Acrysol RM2020 (Dow Corning) & Thickening agent & 1.38 \\
Water & - & Solvent & 4.6 \\
\hline
\end{tabular}

TABLE 2: Industrial colorants.

\begin{tabular}{lccc}
\hline Colorant & Pigment & Color & Pigment content in colorant \% \\
\hline Coltec C LS Blue (CPS Color) & Alpha isomer of copper phthalocyanine & Blue (PB 15:1) & 8 \\
Temacolor W CH9 (CPS Color) & Carbon black & Black strong (PBk7) & 16 \\
Coltec C BS Magenta (CPS Color) & 2,9 dimethyl quinacridone & Magenta (PR122) & 30 \\
\hline
\end{tabular}

TABLE 3: Additives for improving orientation of effect pigments in waterborne systems.

\begin{tabular}{|c|c|c|}
\hline No. & Additive & Commercial name \\
\hline 1 & Polyethersiloxane solution in dipropyleneglycol monomethylether & Byk 346 (Byk-Chemie) \\
\hline 2 & Non-ionic emulsion of a modified ethylene-vinyl-acetate (EVA) copolymer wax & Aquatix 8421 (Byk-Chemie) \\
\hline
\end{tabular}

TABLE 4: Formulations.

\begin{tabular}{|c|c|c|c|c|}
\hline Formulation & Description & $\begin{array}{l}\mathrm{g} \mathrm{CNC/g} \\
\text { varnish }\end{array}$ & $\begin{array}{l}\text { \% Colorant } \\
(\mathrm{w} / \mathrm{w})\end{array}$ & $\begin{array}{l}\% \text { Additive } \\
(\mathrm{w} / \mathrm{w})\end{array}$ \\
\hline $\bar{A}$ & Non-sonicated CNC suspension & - & - & - \\
\hline $\mathrm{B}$ & Sonicated CNC suspension & - & - & - \\
\hline $\mathrm{C}$ & Varnish in B suspension & 1.25 & & \\
\hline $\mathrm{D}$ & Blue colorant in B suspension & - & 0.2 & - \\
\hline $\mathrm{E}$ & Black colorant in B suspension & - & 0.2 & - \\
\hline $\mathrm{F}$ & Magenta colorant in B suspension & - & 0.2 & - \\
\hline G & Mixture of varnish, blue colorant and B suspension & 1.25 & 0.2 & - \\
\hline $\mathrm{H}$ & Mixture of varnish, blue colorant, additive no. 1 and B suspension & 1.25 & 0.2 & 0.5 \\
\hline I & Mixture of varnish, blue colorant, additive no. 2 and B suspension & 1.25 & 0.2 & 0.5 \\
\hline $\mathrm{J}$ & Mixture of varnish, black colorant and B suspension & 1.25 & 0.2 & - \\
\hline $\mathrm{K}$ & Mixture of varnish, black colorant, additive no. 1 and B suspension & 1.25 & 0.2 & 0.5 \\
\hline $\mathrm{L}$ & Mixture of varnish, magenta colorant and B suspension & 1.25 & 0.2 & - \\
\hline M & Mixture of varnish, magenta colorant, additive no. 1 and B suspension & 1.25 & 0.2 & 0.5 \\
\hline $\mathrm{N}$ & $\begin{array}{l}\text { Mixture of varnish, magenta and black colorants }(1: 1) \text {, additive no. } 1 \\
\text { and B suspension }\end{array}$ & 1.25 & 0.4 & 0.5 \\
\hline $\mathrm{O}$ & $\begin{array}{l}\text { Mixture of varnish, blue and black colorants (1:1), additive no. } 1 \text { and } \\
\text { B suspension }\end{array}$ & 1.25 & 0.4 & 0.5 \\
\hline
\end{tabular}

control in our studies has a second coat, the varnish without CNC, where the wet film thickness was also 75-80 $\mu \mathrm{m}$. After water evaporation, each coat was UV cured with an Ayotte oven equipped with a mercury lamp. Spectral intensity of the lamp was set at $900 \mathrm{~mJ} / \mathrm{cm}^{2}$.

A goniospectrophotometer Model GSP-1B with GCMS3B optical measurement unit (Murakami color Research Laboratory, Tokyo, Japan) was used to quantify reflection color differences in free films containing CNC. Following instrument calibration against a standard white tile, the films were placed against a matte black background and held flat with removable tape. The color parameters, that is, $\mathrm{L}^{*}$ (lightness), $\mathrm{a}^{*}$ (green-red coordinate) and $\mathrm{b}^{*}$ (blue-yellow coordinate), were measured under $45^{\circ}$ incident illumination over a reflection range of 0 to $80^{\circ}$ in $5^{\circ}$ steps. A standard D65 illuminant was used.

A portable multiangle spectrophotometer, MA98 from XRite (Manutrol Inc., Canada), was used to measure the color parameters $\mathrm{L}^{*}, \mathrm{a}^{*}$, and $\mathrm{b}^{*}$ at $45^{\circ}$ incident illumination for the coatings applied onto wood. The aspecular viewing angles 
were: $15^{\circ}, 25^{\circ}, 45^{\circ}, 75^{\circ}$, and $110^{\circ}$. A standard D65 illuminant was used. Five measurements of color parameters $L^{*}, a^{*}$, and $\mathrm{b}^{*}$ at different viewing angles were obtained from each sample.

The color differences obtained against the black standard were further employed to illustrate color travel and to generate flop index values.

CD spectra were measured with a Jasco J815 Circular Dichroism Spectropolarimeter. The specimens were analyzed in a $1 \mathrm{~mm}$ path length rectangular cell that was set perpendicularly to the incident cross-polarized light and scanned at $100 \mathrm{~nm} / \mathrm{min}$ with a step resolution of 0.2 and $1 \mathrm{~nm}$ bandwidth.

Photomicrographs were taken at the surface of the free films at 20X magnification with an Axio Imager 2 (Zeiss) optical microscope equipped with a camera and crossedpolarizers.

The zeta potential of CNC suspensions, mixtures of CNC with colorants, and coating formulations was determined with a Zetasizer Nano from Malvern (Worcestershire United Kingdom), which has a zeta potential analyzer based on electrophoretic light scatting. A $4 \mathrm{~mW} \mathrm{He}-\mathrm{Ne}$ laser source with $633 \mathrm{~nm}$ wavelength was used as light source. All measurements were performed at $25^{\circ} \mathrm{C}$.

\section{Results and Discussion}

3.1. Film Characterization by Optical Microscopy under Polarized Light. The films prepared with the CNC suspension, colorants, varnish and additives are shown in Figures 1, 2 and 3. Polarized optical micrographs of the films cast from the CNC suspension, the sonicated CNC suspension, and different mixtures prepared from a sonicated CNC suspension are shown in Figure 4 . The intensity of the chiral interaction between particles is characterized by the chiral nematic pitch $P$. Through these micrographs one can visualize the effect of the colorants, additives and varnish on the fingerprint pattern of the CNC chiral-nematic organization and quantify the pitch.

Pitch calculation was based on the distance between three successive dark (or light) bands associated with the retardation lines that create the fingerprint patterns [18]. According to Dong et al. [19], the smaller is the pitch, the stronger is the interaction between CNC particles rods. The values of chiral nematic pitch shown in Table 5 represent averages of 10 measurements. The ANOVA results were used to interpret the values of pitch. The Waller-Duncan multiple comparison test highlighted 4 different groups at the 0.05 probability level.

It can be observed that sonication of the $\mathrm{CNC}$ suspension has not increased significantly the chiral nematic pitch. Beck et al. [13] had already established that a high energy input could induce an increase in pitch.

The addition of blue and black colorants to the sonicated CNC suspension reduced pitch in the films cast from formulations $\mathrm{D}$ and $\mathrm{E}$, while the addition of a magenta colorant did not affect the pitch of the film cast from the sonicated CNC suspension (formulation $\mathrm{F}$ ). With the addition of $0.8 \mathrm{~g}$ of varnish per gram of $\mathrm{CNC}$, the chiral nematic pitch of the film
TABLE 5: Effect of adding varnish, colorants and additives on the chiral nematic.

\begin{tabular}{lc}
\hline Formulation & $\begin{array}{c}\text { Chiral nematic pitch, } \\
\mu \mathrm{m}(\text { standard deviation })\end{array}$ \\
\hline A & $4.7(0.45)$ \\
B & $5.0(0.80)$ \\
C & $3.8(0.25)$ \\
D & $4.2(0.56)$ \\
E & $4.1(0.62)$ \\
F & $4.9(0.52)$ \\
G & $5.9(0.78)$ \\
H & $6.5(0.62)$ \\
I & $5.9(0.77)$ \\
J & $4.7(0.77)$ \\
K & $4.9(0.30)$ \\
\hline
\end{tabular}

cast from formulation $\mathrm{C}$ became tighter $(3.8 \mu \mathrm{m})$ than with the film cast from the sonicated CNC suspension $(5 \mu \mathrm{m})$.

In the case of the formulations involving the varnish, the black colorant, and the two additives ( $\mathrm{J}$ and $\mathrm{K}$ formulations) the pitch has not increased significantly in comparison with the sonicated CNC suspension. When the blue colorant, varnish, and the two additives were added ( $G, H$, and $I)$, the pitch has significantly increased in comparison with the formulation of $\mathrm{CNC}$ with varnish ( $\mathrm{C}$ formulation). In the formulation $\mathrm{H}$, for example, the addition of siloxane and the blue colorant caused the pitch to reach $6.5 \mu \mathrm{m}$. The addition of a copolymer wax (additive no. 2) induced a tighter pitch than with siloxane (additive no. 1). These additives were chosen because their structure was particularly well suited to improving the orientation of effect pigments. Using optical microscopy equipped with polarized light, one could discriminate the additives capable of improving the iridescence effect of the CNC rod-like particles due to changes in chiral nematic pitch.

3.2. Characterization of Liquid Formulations and Films by Circular Dichroism. CD spectra were measured for aqueous suspensions (Figure 5) and for solid films (Figure 6).

The CD signal of the CNC suspension was found to be negative in the UV region (Figure 5). No significant signal was detected in the visible region. No differences in signal were observed for the sonicated CNC suspension. The addition of the blue and black colorants had no effect on the $\mathrm{CD}$ signal of the CNC suspension. A very weak positive signal in the visible region was obtained for the mixture based on the sonicated CNC suspension and the varnish (formulation C). The addition of the blue and black colorants besides the varnish (formulations $G$ and J) produced a very weak positive signal in the UV region and a negative signal in the visible region, indicating a right-handed arrangement in the colloidal suspensions. The addition of siloxane additive produced left- and right-handed arrangements by giving 


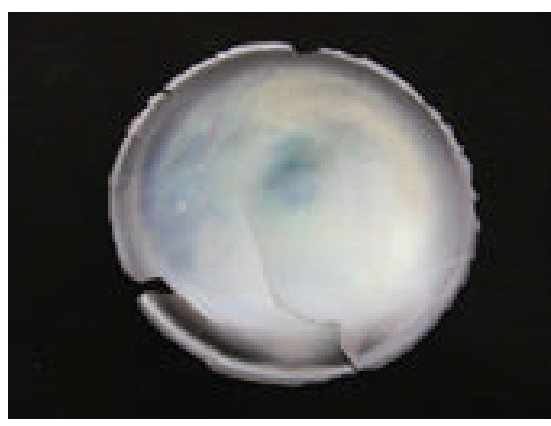

(A)

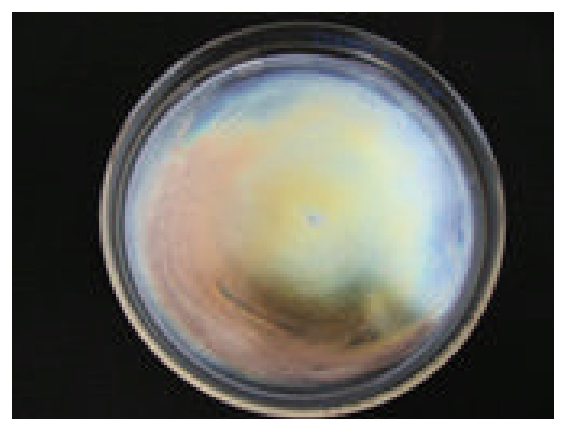

(B)

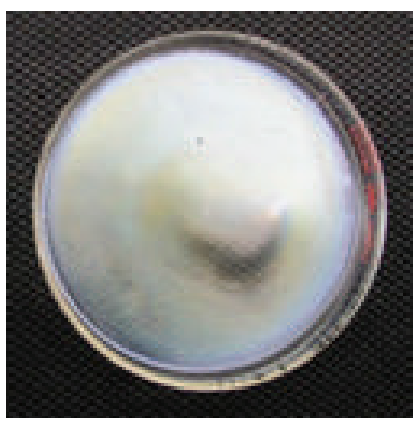

(C)

Figure 1: Films prepared from CNC suspension (A), sonicated suspension (B), and sonicated suspension with varnish (C).

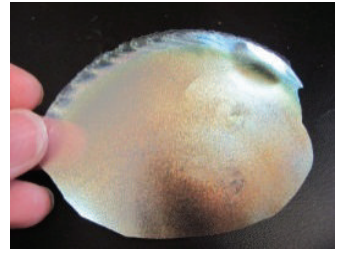

(B)

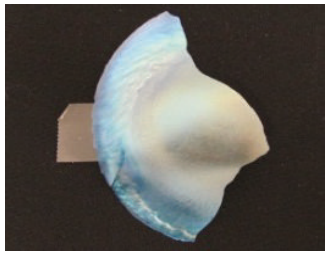

(D)

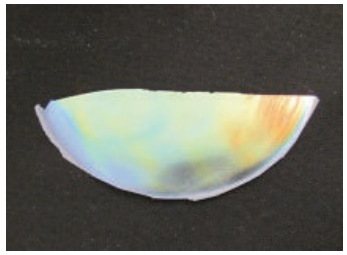

(E)

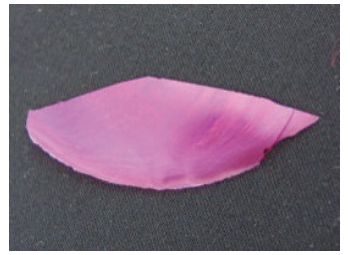

(F)

Figure 2: Films prepared from sonicated CNC suspension (B) with addition of blue (D), black (E), and magenta (F) colorants.

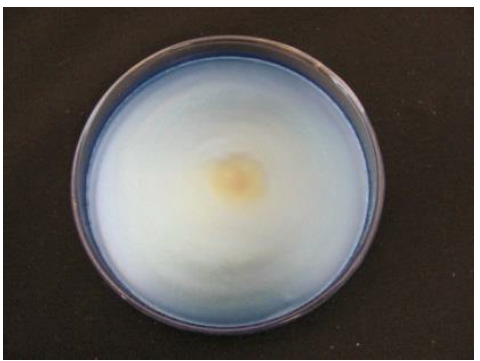

(G)

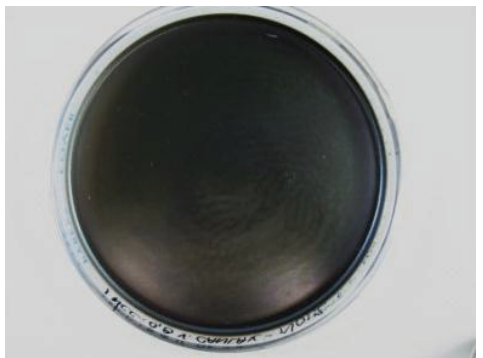

(J)

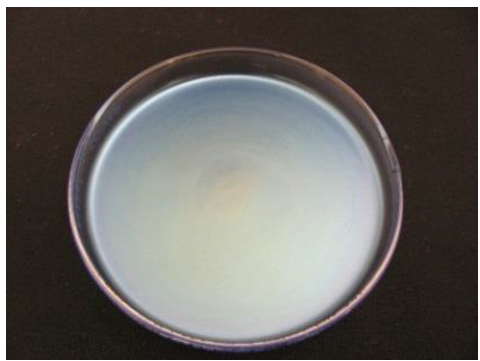

(H)

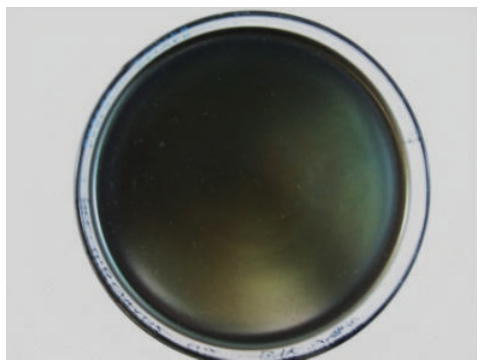

(K)

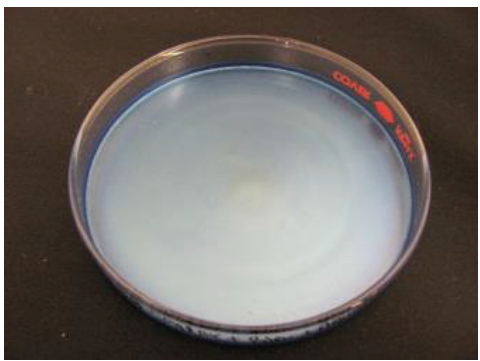

(I)

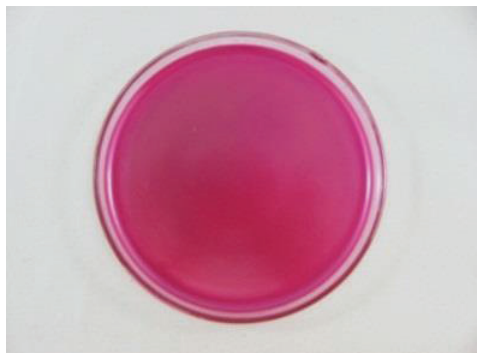

(M)

FIGURE 3: Films prepared with CNC suspension, varnish, colorants, and additives (formulation identification as per Table 4).

rise to stronger negative and positive signals in formulation $\mathrm{K}$, with a black colorant. Formulation $\mathrm{H}$ showed a righthanded orientation through a negative CD signal. It therefore appeared that the siloxane additive tended to orient the rodlike CNC in colloidal suspension before it reached the critical concentration necessary for the particles to self-orient in a chiral nematic ordered structure.

The solid films based on CNC showed strong positive CD signals, off scale in some cases, which indicated that all the formulations containing $\mathrm{CNC}$ had undergone an isotropic to nematic phase transition having a left-handed structure (Figure 6).

The film produced from the aqueous nonsonicated CNC suspension exhibited strong absorption in the UV and visible regions. The film produced from the sonicated aqueous $\mathrm{CNC}$ suspension exhibited a red shift by comparison with that produced from the non-sonicated suspension, which suggests elongation in the cholesteric pitch of the helical structure. 


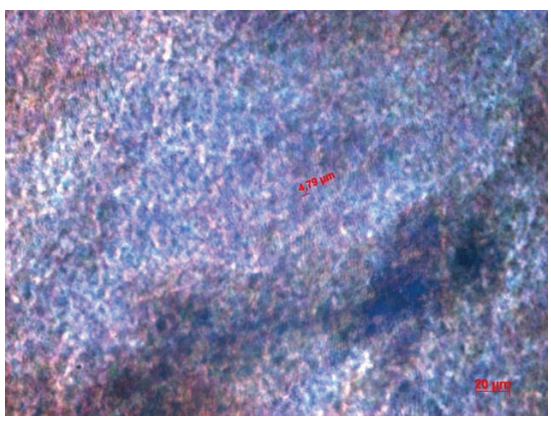

(A)

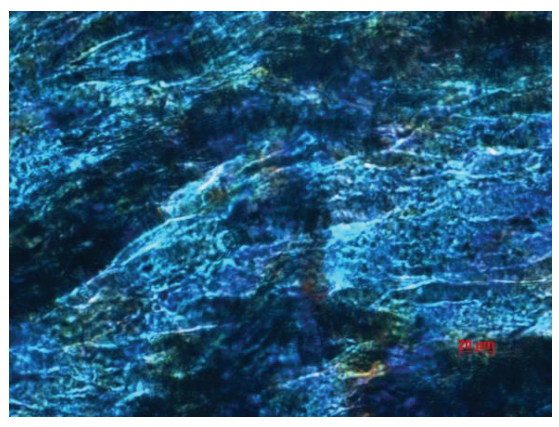

(D)

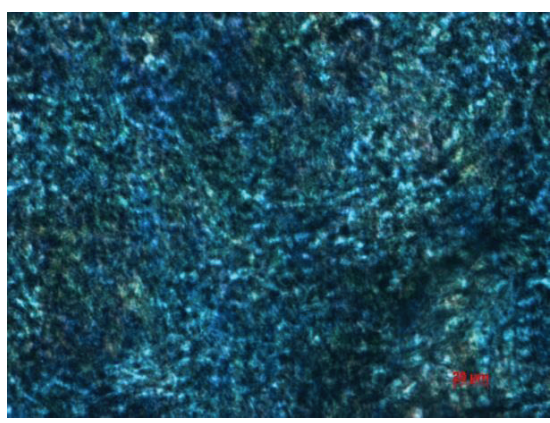

(G)

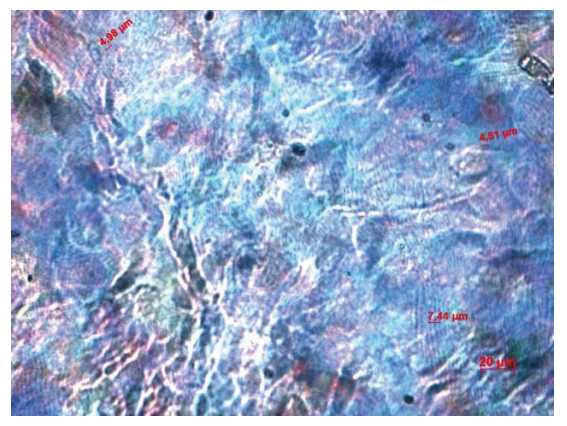

(B)

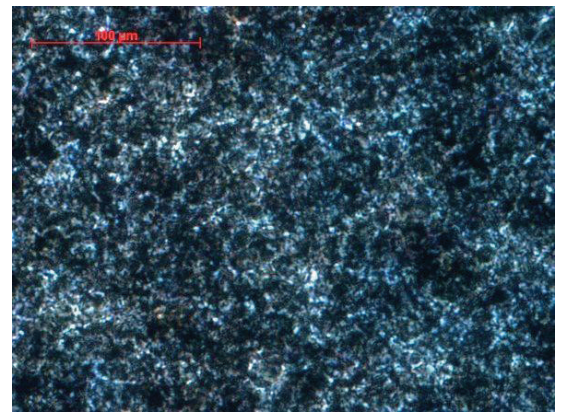

(E)

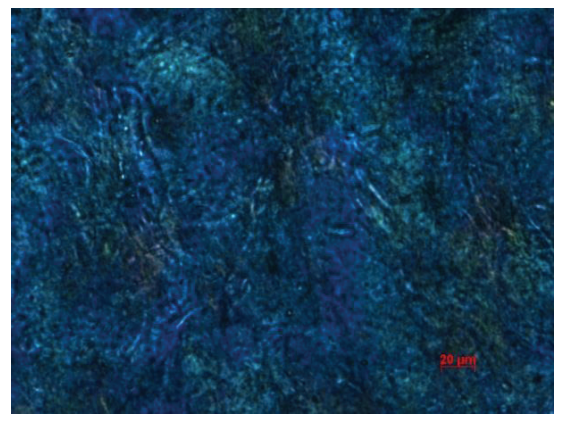

$(\mathrm{H})$

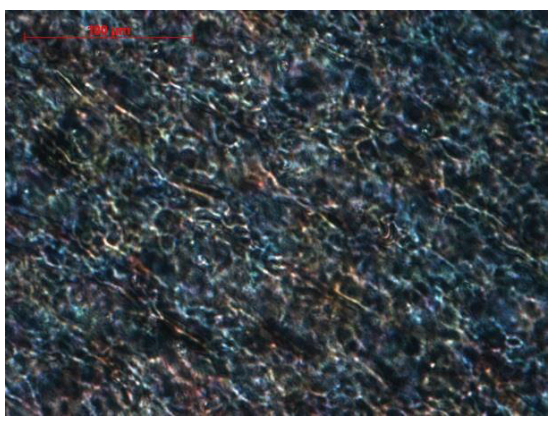

(C)

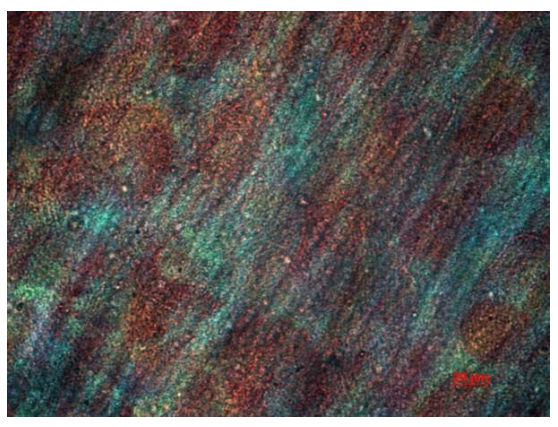

(F)

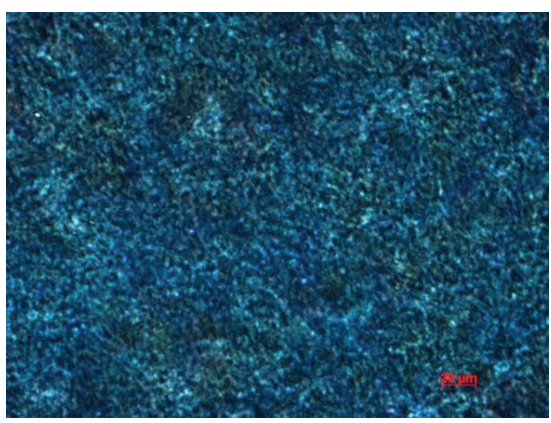

(I)

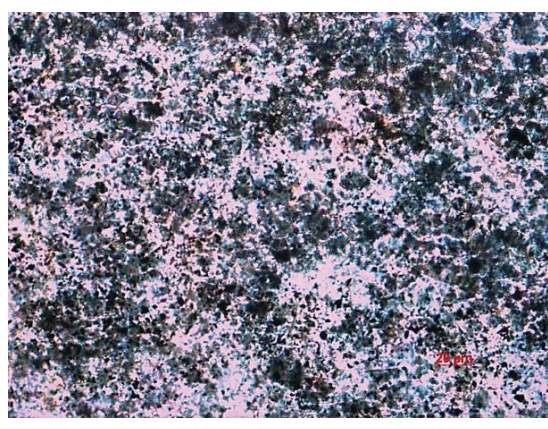

(J)

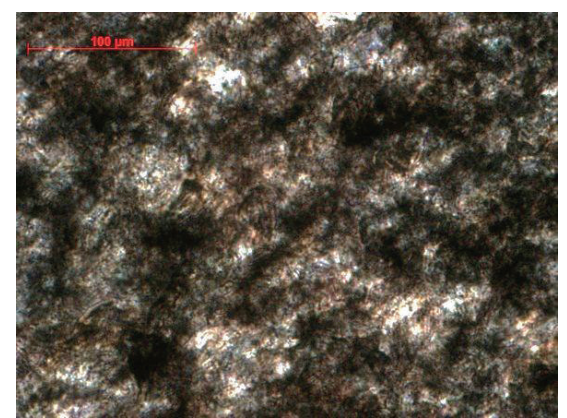

$(\mathrm{K})$

FIgURE 4: Micrographs of optical microscopy with polarized light at 20X magnification (formulation identification as per Table 4).

The addition of the varnish led to a broader CD band than with the sonicated CNC suspension [20]. This may be due to the formation of a structure composed of chiral nematic polydomains [21] or to imperfect orientation of the chiral nematic phase in the solid film. The urethane-acrylate latex particles contained in the varnish formulation can disturb the alignment of CNC rods because of their large size (100$300 \mathrm{~nm}$ ). According to Zou et al. [14] the latex particles can create polymer "islands" between ordered domains of CNC aggregates, causing weakening of iridescence.

The CD band of film cast from a mixture of a sonicated CNC suspension with the black colorant (formulation E) follows almost the same path as the film cast from the sonicated CNC suspension. This behavior was confirmed by almost same pitch found for those two formulations displayed in Table 5. The optical effects occurring in the CNC films with 


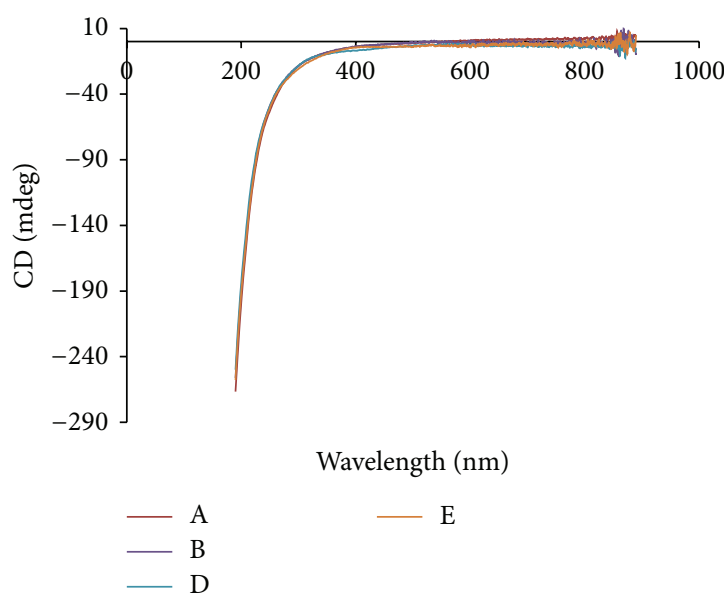

(a)

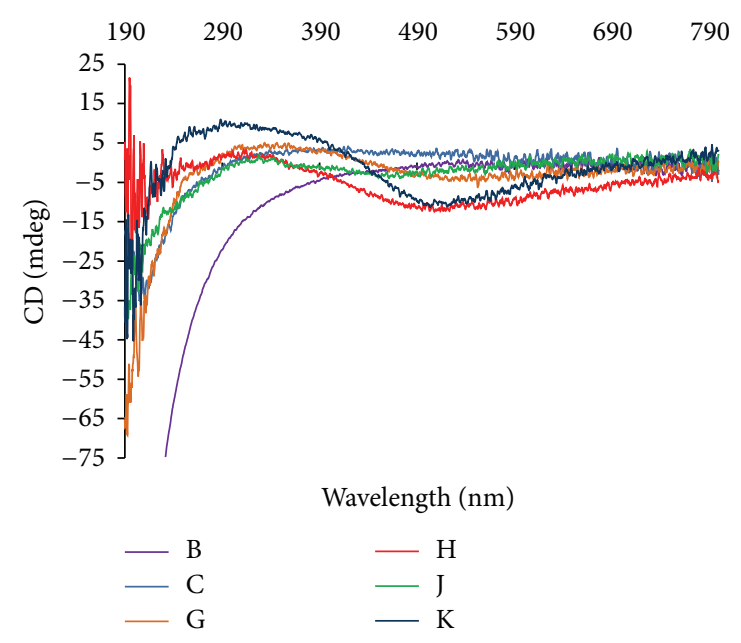

(b)

FIgURE 5: Circular dichroism (CD) spectra of formulations with CNC suspension including blue and black colorants (a) and with varnish, colorants, and additives (b).

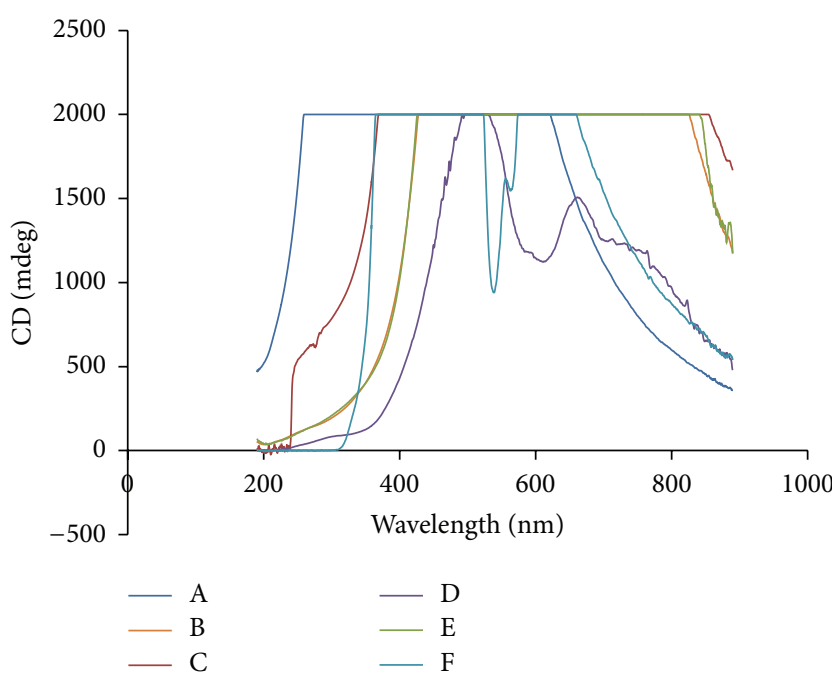

FIGURE 6: Circular dichroism (CD) spectra of films containing CNC, varnish, and colorants.

colorants resulted from the reflection of circularly polarized light due to the chiral nematic structure and the absorption of the circularly polarized light due to the presence of pigments.

The film cast from a mixture of a sonicated CNC suspension and blue colorant showed the smallest positive $\mathrm{CD}$ signal. The two peaks, at 490 and $689 \mathrm{~nm}$, are due to the color appearance of $\alpha$-copper phthalocyanine which is a blue pigment with red shade (PB 15:1). In this case the pitch decreased, and the iridescent effect was smaller than with the black colorant. Likewise the CD band of the films with a magenta colorant exhibited two peaks, at 450 and $635 \mathrm{~nm}$, corresponding to the blue and red colors. CD band shows that the pitch of the structure found in the film cast from formulation $\mathrm{F}$ is greater than that from formulation $\mathrm{D}$. tion of Colorants, Varnish and Siloxane Additive. The stability of a suspension is governed by the degree of surface charge. Measurements of the zeta potential indicate the surface charge on colloidal particles. Suspensions are stable; that is, particles do not aggregate (or unstable, particles aggregate) depending on the magnitude of the zeta potential of the particles [22]. Particles with zeta potentials more positive than $+30 \mathrm{mV}$ or more negative than $-30 \mathrm{mV}$ are normally considered stable.

In an CNC suspension the degree of surface charge is determined by sulfate ester groups. The degree of sulfation is known to affect the reflection color of CNC films [9]. As can be observed in Table 6 , a strong negative zeta potential value $(-76 \mathrm{mV})$ characterized the CNC suspension. The sonicated suspension also yielded a strong negative zeta potential $(-62 \mathrm{mV})$. Therefore, the two suspensions are considered stable. Sonication affected the electrostatic properties of the CNC suspension with insignificant damage to the surface charge density. The zeta potential was kept around $-62 \mathrm{~V}$ when the blue and magenta colorants were added to the sonicated CNC suspension (formulations D and F). Organic pigments such as copper phthalocyanine in the Pigment Blue 15:1 and carbon black are low polar pigments and do not carry surface charges. Despite the fact that a commercial colorant contains stabilizer agents, dispersants, or solvents, the ionic strength of the blue and magenta colorants has preserved the nonionic behavior of Pigment Blue 15:1 and Pigment Red 122. When the black colorant was added, intercalation of the carbon black modified the density of the sulfate groups and induced a less negative charge on the CNC surface $(-37 \mathrm{mV})$. Consequently, the three colorants used in the formulations had no dramatic effect on the stability of the CNC suspensions.

The mixture of the CNC suspension with the varnish based on an urethane-acrylate dispersion changed the surface charge of the CNC particles. The zeta potential was found to be $-22 \mathrm{mV}$ as the mixture became unstable. The formulations with varnish and colorants, $G$ and J, showed an increase in zeta potential in a different way. The siloxane additive gave 
TABLE 6: Effect of adding varnish, colorants and additives on zeta potential of CNC suspension.

\begin{tabular}{lc}
\hline Formulation & Zeta potential, $\mathrm{mV}$ \\
\hline A & -76.0 \\
B & -61.5 \\
C & -22.9 \\
D & -62.6 \\
E & -37.0 \\
F & -62.2 \\
G & -14.5 \\
H & -16.2 \\
J & -10.7 \\
K & -0.7 \\
\hline
\end{tabular}

rise to critical instability (the zeta potential was $0 \mathrm{mV}$ ) in formulation $\mathrm{K}$ with the black colorant containing carbon black. The additive triggered flocculation of the rod-like CNC particles, and agglomeration of the carbon black pigment, possibly leading to a separation phase at any time.

The polarity of the polyether chains of the siloxane additive proved to have more impact on the formulation containing carbon black, as this kind of pigment orients itself in a plate-like structure.

3.4. Color Travel of the Free Films. Angle-dependent spectrophotometric testing was required to characterize special effect pigments in free films. The color dynamics resulting from a combination of geometries and pigments can be illustrated by color changes (color travel). As CNC acts as an interference effect pigment, the $\mathrm{a}^{*} \mathrm{~b}^{*}$ diagram illustrates color changes through a color travel.

Figures 7 and 8 display the shift caused by keeping the illumination angle constant at $45^{\circ}$ and varying the specular angle in the range of 0 to $80^{\circ}$ in $5^{\circ}$ steps.

As observed in Figure 7, the film prepared from the sonicated CNC suspension (formulation B) exhibited a red shift with a lighter shade than seen with the nonsonicated CNC suspension (formulation A). The color travel of the films with blue and magenta colorants (formulations D and F) was enhanced. The blue colorant induced the most significant light to dark color travel. Color travel was less pronounced in the film prepared from formulation E, with the black colorant, than in the film based on the sonicated CNC suspension.

When the varnish was mixed with the CNC suspension, the color travel of the film decreased (Figure 8). Addition of the blue colorant (formulation $\mathrm{G}$ ) enhanced color travel by comparison with formulation C. As can be seen in Figure 8, the two additives used to improve CNC orientation in the film (formulations $\mathrm{H}, \mathrm{I}$, and $\mathrm{K}$ ) enhanced color travel by comparison with formulation $\mathrm{G}$. The color change was more evident in the $\mathrm{a}^{*} \mathrm{~b}^{*}$ diagram when the siloxane additive was involved (formulation $\mathrm{H}$ ). Figures 9 and 10 show $\mathrm{L}^{*}$ changes as the viewing angle varies. Of all the colorants used in the tests, the blue colorant was most effective in enhancing dark to light color travel (Figure 9). When the blue colorant was present in formulations containing varnish, color travel was

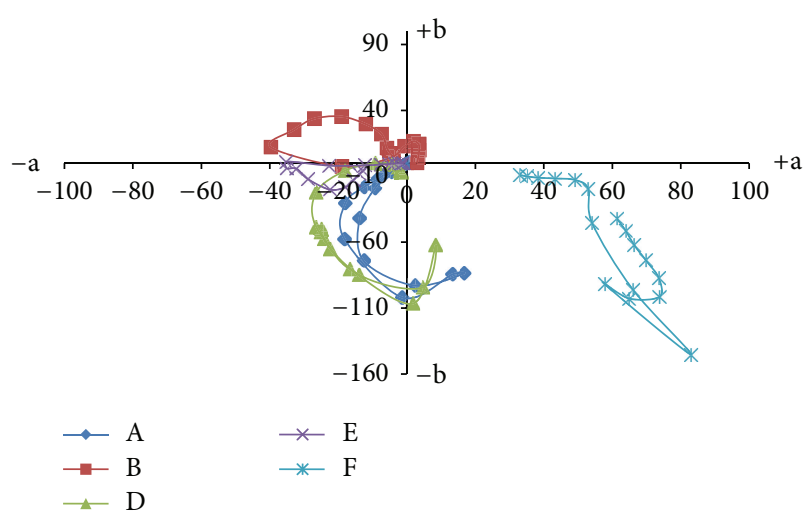

Figure 7: Color travel through $\mathrm{a}^{*} \mathrm{~b}^{*}$ diagrams of free films with CNC suspension and colorants.

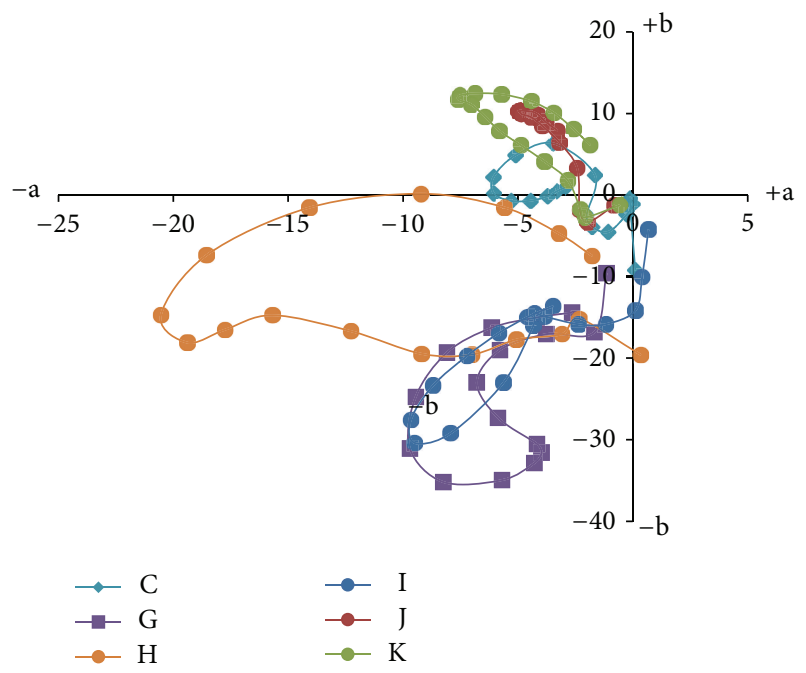

FIGURE 8: Color travel through $\mathrm{a}^{*} \mathrm{~b}^{*}$ diagrams of free films with $\mathrm{CNC}$ suspension, varnish, colorants, and additives.

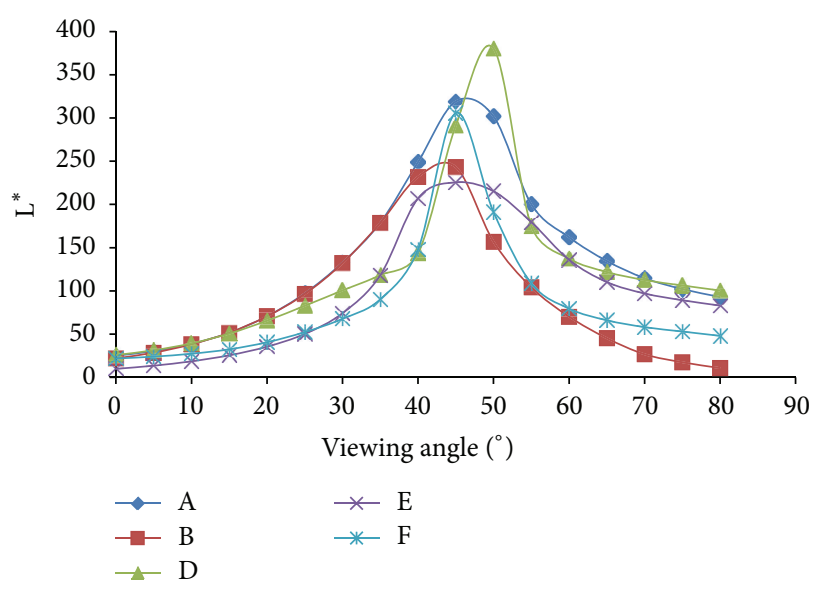

FIGURE 9: Color travel through $\mathrm{L}^{*}$ changes of free films based on CNC suspension and colorants. 


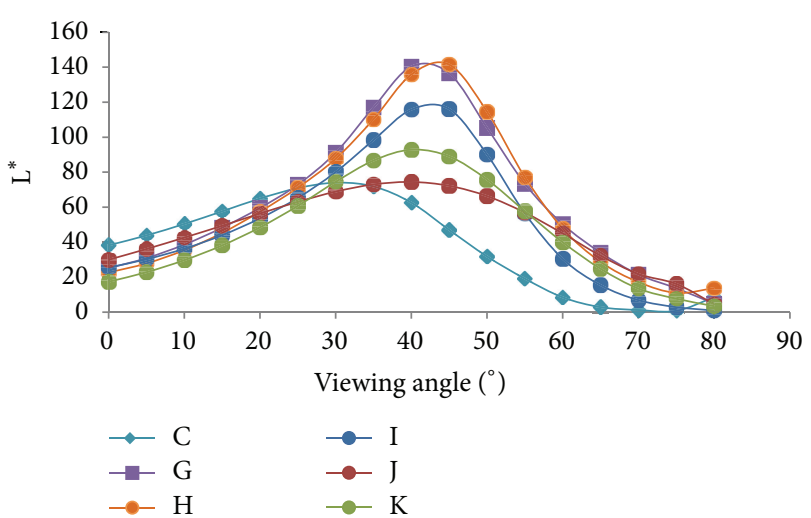

FIGURE 10: Color travel through $\mathrm{L}^{*}$ changes of free films based on $\mathrm{CNC}$ suspension, varnish, colorants, and additives.

also enhanced from dark to lighter shades (Figure 10). All the formulations containing varnish clearly exhibited weaker color travel than those without. However, resin content optimization should also consider the fact that CNC-based coatings designed for wood applications are expected to provide a degree of flexibility as well as appearance attributes.

3.5. Color Travel and Flop Index of Wood Coatings. Prior to application of the coating formulations onto sugar maple wood specimens, several tests were conducted. The special effect appearance of the coatings was investigated with a portable multiangle spectrophotometer.

The flop index (FI) with standard deviation was automatically calculated with the X-Color QC software of the X-Rite equipment. The following formula was used:

$$
\mathrm{FI}=\frac{2.69\left(\mathrm{~L}^{*} 15-\mathrm{L}^{*} 110\right)^{1.11}}{\left(\mathrm{~L}^{*} 45\right)^{0.86}} .
$$

The flop indexes of the coatings applied to the wood specimens were calculated for different wet thicknesses obtained by pulverization (Figure 11). The flop index increased with wet thickness in the case of formulation C (UV varnish in sonicated CNC aqueous solution). In view of the low $\mathrm{CNC}$ concentration $(5.3 \%)$ in the initial formulations, retention of iridescence required higher $\mathrm{CNC}$ concentration in the wet film. The CNC-containing wet layer had to be thicker than $250 \mu \mathrm{m}$ to ensure satisfactory special visual effect on the wooden substrate. Consequently, the following coatings were applied in coats of $380 \mu \mathrm{m}$. This wet thickness yielded a dry film of barely $30 \mu \mathrm{m}$ in thickness. As the most effective reflection for an $\mathrm{CNC}$ film is achieved when the dry film thickness reaches $10 \mu \mathrm{m}$, the first layer with CNC was sufficient to induce effective reflection but, given the light color of sugar maple, the wood did not benefit from the strong color travel.

Images of the coatings applied onto sugar maple wood are shown in Figure 12. The special effect appearance through color travel of the coatings prepared with formulations $\mathrm{C}, \mathrm{H}$, $\mathrm{K}, \mathrm{N}, \mathrm{O}$, and varnish (control) are shown in the Figures 13 and 14. For each formulation, the averages of color parameters $\mathrm{L}^{*}$,

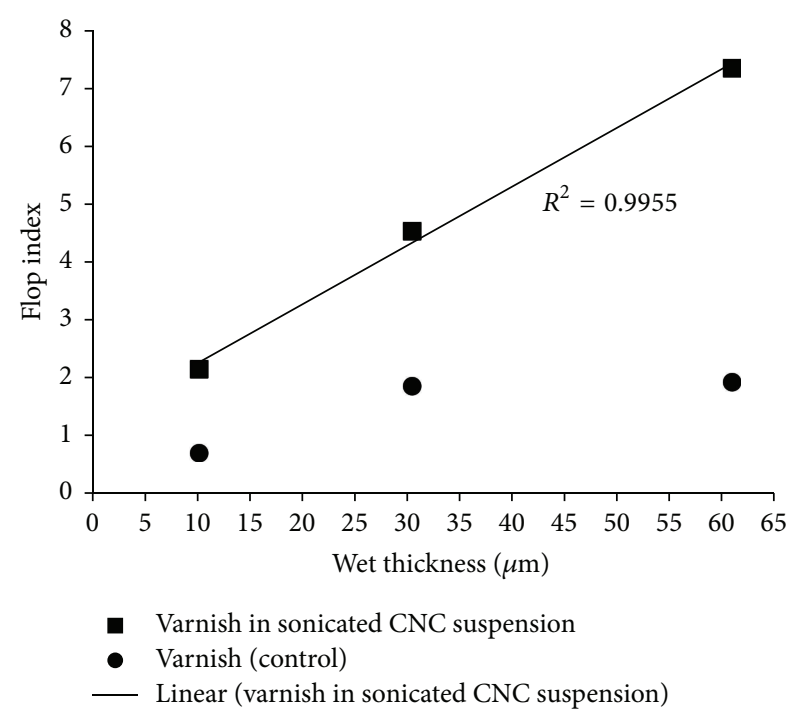

FIGURE 11: Effect of wet thickness on the flop index of coating C.

$\mathrm{a}^{*}$, and $\mathrm{b}^{*}$ at different viewing angles were obtained from five samples.

In the $\mathrm{a}^{*} \mathrm{~b}^{*}$ chromaticity plane color travel was more intense for the coatings prepared with varnish, $\mathrm{CNC}$, and black colorant, where the color had traveled through three quadrants (formulations $\mathrm{K}$ and O) (Figure 13). Color travel was clearly the shortest with the varnish among all finishing systems. The finishing systems prepared with sonicated CNC suspension and varnish, without colorants (coating C), showed a pronounced red shift as the viewing angle increased. A red shift was also observed for coating $\mathrm{N}$, which employed a mixture of magenta and black colorants. The finishing coating based on formulation $\mathrm{H}$ indicated color travel from blue to green shades.

Oriented CNC in the colored coat produced a light to dark color travel appearance that could be observed on the $\mathrm{L}^{*}$ axis (Figure 14). Color travel was more pronounced in the CNC-based finishing systems than in the control.

The flop indexes of finishing systems applied to wood are shown in Table 7. Flop is caused by the predominantly parallel orientation of the $\mathrm{CNC}$ rods in the coating, which increases reflection in the specular direction. The finishing systems contained CNC and colorants exhibited higher flop indexes than the formulation using a sonicated CNC suspension and varnish (formulation C). The highest flop index values were obtained in formulations employing the black colorant. The addition of blue or magenta colorant with the black colorant in an CNC nonsonicated suspension besides the varnish yielded high flop indexes, with values equivalent to those of coatings having high metallic effect [23].

\section{Conclusions}

Experimental wood coatings were developed using CNC as effect pigment. As thick layers of the originally dilute aqueous CNC suspension had to be applied to retain 


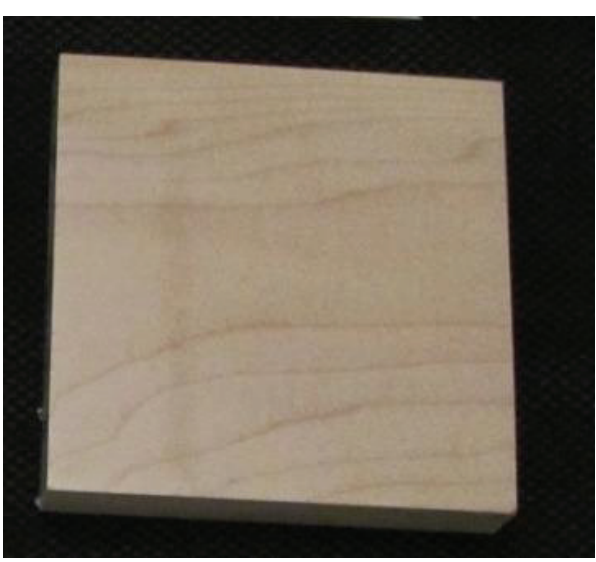

Varnish

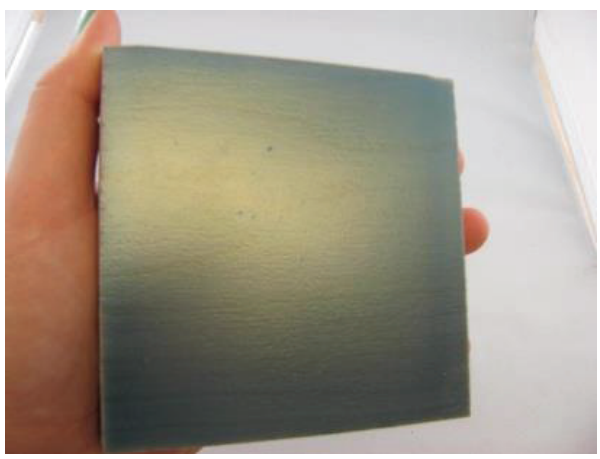

$(\mathrm{H})$

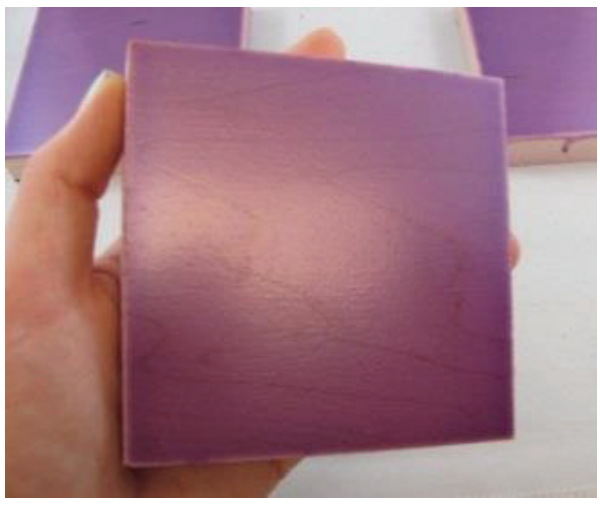

(N)

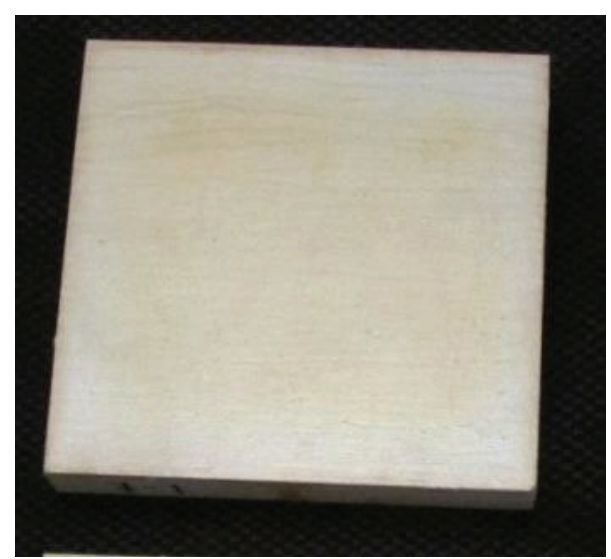

(C)

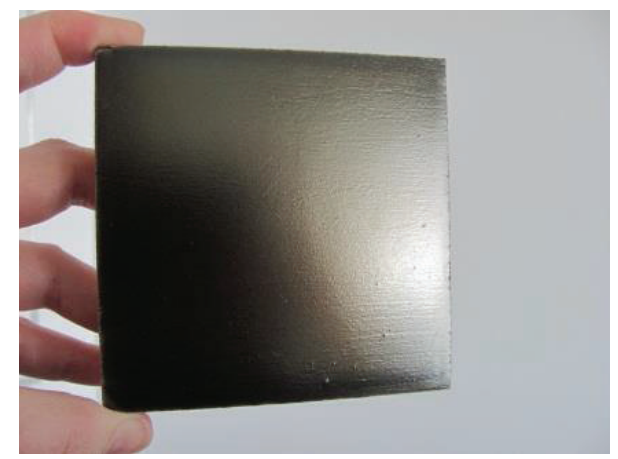

(K)

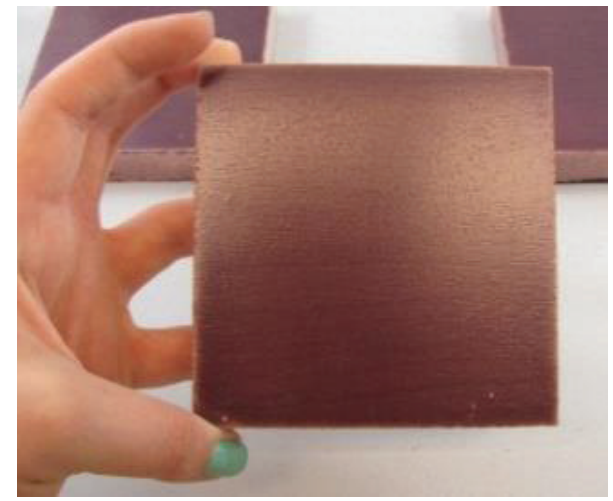

(O)

FIGURE 12: Wood coatings prepared with formulations of varnish, C, H, K, N and O.

the iridescent effect, practical difficulties were experienced due to insufficient workability. The iridescent effect of the sonicated CNC-containing films depended on the wet thickness of the layer, which was correlated with CNC concentration in the dry film. Chiral nematic pitch changes, broadening of CD spectra, fingerprint patterns degradation, and CNC surface charge changes were correlated with the iridescent effect. CNC orientation in a proper position and formation of the stacked planes are essential to generate the right pitch in the CNC helical structure, locking in the chiral nematic structure. The distribution and alignment of the CNC rodlike particles, and their interaction with the polymer matrix as well as with the additives were shown to determine optical effect of the new coatings. The changes in chiral nematic pitch observed through optical microscopy with polarized light were confirmed by the CD spectra.

The iridescent effect of coatings and free films was explained through color travel and flop index. Enhancement of the iridescent effect was shown to depend on the nature and concentration of the colorant/pigment used and the additives selected to improve CNC orientation in the dry film.

In conclusion, CNC could be successfully used as effect pigment in wood coatings. It offers an original prospect to this renewable resource at a time where novel applications of the pulp and paper are sought. Finishing systems contained CNC, varnish, and colorants can accentuate the attractiveness of 


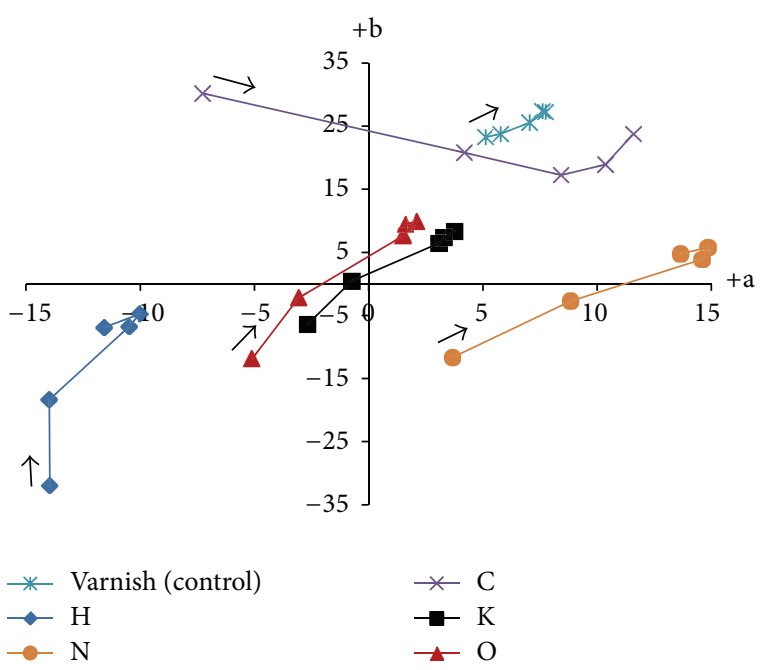

Figure 13: Color travel through $\mathrm{a}^{*} \mathrm{~b}^{*}$ diagrams of finishing systems based on varnish, CNC, blue and black colorants (the arrows shows increasing of viewing angle).

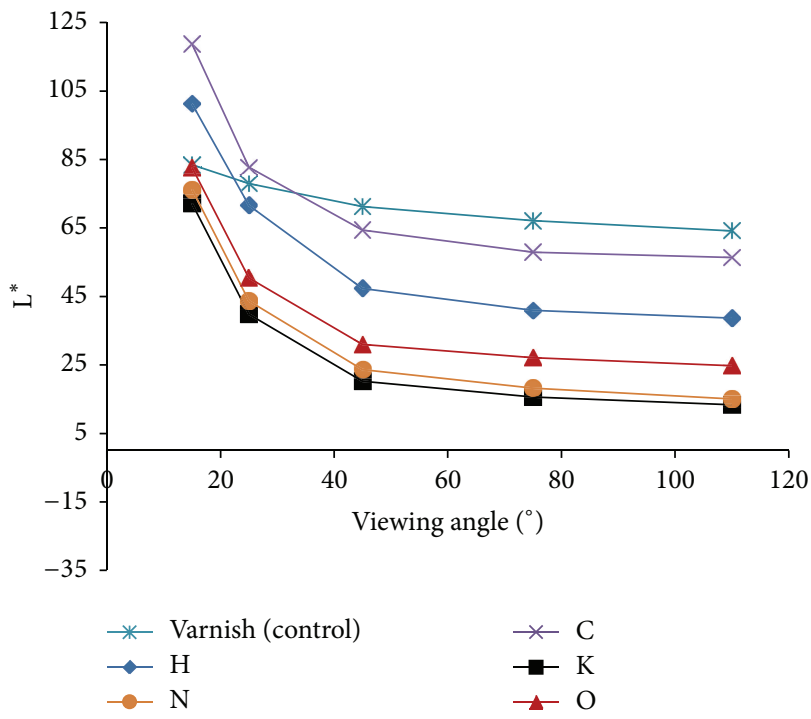

Figure 14: Color travel through $\mathrm{L}^{*}$ changes of finishing systems based on varnish, CNC, blue and black colorants.

TABLE 7: Flop index of finishing systems for wood with standard deviation.

\begin{tabular}{lc}
\hline Finishing system & $\begin{array}{c}\text { Flop index } \\
\text { (standard deviation) }\end{array}$ \\
\hline 2 coats of varnish (control) & $1.92(0.25)$ \\
1 coat of varnish +2 coats of $\mathrm{C}$ formulation & $7.36(0.32)$ \\
1 coat of varnish +2 coats of $\mathrm{H}$ formulation & $9.84(2.39)$ \\
1 coat of varnish +2 coats of $\mathrm{K}$ formulation & $18.82(2.20)$ \\
1 coat of varnish +2 coats of $\mathrm{M}$ formulation & $8.96(0.7)$ \\
1 coat of varnish +2 coats of $\mathrm{N}$ formulation & $17.04(0.68)$ \\
1 coat of varnish +2 coats of $\mathrm{O}$ formulation & $12.87(2.06)$ \\
\hline
\end{tabular}

wooden surfaces, by bringing out the special grain of various types of wood.

\section{Acknowledgments}

The authors are grateful to ArboraNano and Natural Sciences and Engineering Research Council of Canada (NSERC) for the financial support. The authors would like to thank also Stephanie Beck from FPInnovations for technical support (Pulp, Paper and Bioproducts division, Pointe Claire, Québec, Canada).

\section{References}

[1] B. G. Rånby, "III. Fibrous macromolecular systems. Cellulose and muscle. The colloidal properties of cellulose micelles," Discussions of the Faraday Society, vol. 11, pp. 158-164, 1951.

[2] R. H. Marchessault, F. F. Morehead, and M. J. Koch, "Some hydrodynamic properties of neutral suspensions of cellulose crystallites as related to size and shape," Journal of Colloid Science, vol. 16, no. 4, pp. 327-344, 1961.

[3] S. Beck-Candanedo, M. Roman, and D. G. Gray, "Effect of reaction conditions on the properties and behavior of wood cellulose nanocrystal suspensions," Biomacromolecules, vol. 6, no. 2, pp. 1048-1054, 2005.

[4] V. Favier, H. Chanzy, and J. Y. Cavaillé, "Polymer nanocomposites reinforced by cellulose whiskers," Macromolecules, vol. 28, no. 18 , pp. 6365-6367, 1995.

[5] X. D. Cao, H. Dong, and C. M. Li, "New nanocomposite materials reinforced with flax cellulose nanocrystals in waterborne polyurethane," Biomacromolecules, vol. 8, no. 3, pp. 899-904, 2007.

[6] X. M. Dong, J. F. Revol, and D. G. Gray, "Effect of microcrystallite preparation conditions on the formation of colloid crystals of cellulose," Cellulose, vol. 5, no. 1, pp. 19-32, 1998.

[7] J. F. Revol, H. Bradford, J. Giasson, R. H. Marchessault, and D. G. Gray, "Helicoidal self-ordering of cellulose microfibrils in aqueous suspension," International Journal of Biological Macromolecules, vol. 14, no. 3, pp. 170-172, 1992.

[8] H. de Vries, "Rotatory power and other optical properties of certain liquid crystals," Acta Crystallographica, vol. 4, part 3, pp. 219-226, 1951.

[9] J. F. Revol, L. Godbout, and D. G. Gray, "Solid self-assembled films of cellulose with chiral nematic order and optically variable properties," Journal of Pulp and Paper Science, vol. 24, no. 5, pp. 146-149, 1998.

[10] A. Roger and B. Norden, Circular Dichroism and Linear Dichroism, Oxford University Press, Oxford, UK, 1997.

[11] M. Hatano, "Induced circular dichroism in liquid crystalline phases," in Induced Circular Dichroism in Biopolymer-Dye Systems, S. Okamura, Ed., pp. 94-102, Springer, Berlin, Germany, 1986.

[12] J. Pan, W. Hamad, and S. K. Straus, "Parameters affecting the chiral nematic phase of nanocrystalline cellulose films," Macromolecules, vol. 43, no. 8, pp. 3851-3858, 2010.

[13] S. Beck, J. Bouchard, and R. Berry, "Controlling the reflection wavelength of iridescent solid films of nanocrystalline cellulose," Biomacromolecules, vol. 12, no. 1, pp. 167-172, 2011.

[14] X. Zou, X. Tan, and R. Berry, "Flexible, iridescent nanocrystalline cellulose film, and method for preparation," WO, 2010/124378 A1, 2010.

[15] G. Pfaff, Special Effect Pigments, European Coatings Tech Files, Vincentz Network, Hannover, Germany, 2nd edition, 2008. 
[16] P. Vukusic and J. R. Sambles, "Photonic structures in biology," Nature, vol. 424, no. 6950, pp. 852-855, 2003.

[17] S. Beck, J. Bouchard, and R. Berry, "Iridescent solid nanocrystalline cellulose films incorporating patterns and method for their production," US/20100151159 A1, 2010.

[18] Y. P. Zhang, V. P. Chodavarapu, A. G. Kirk, and M. P. Andrews, "Nanocrystalline cellulose for covert optical encryption," Journal of Nanophotonics, vol. 6, pp. 1-8, 2012.

[19] X. M. Dong, T. Kimura, J. F. Revol, and D. G. Gray, "Effects of ionic strength on the isotropic-chiral nematic phase transition of suspensions of cellulose crystallites," Langmuir, vol. 12, no. 8, pp. 2076-2082, 1996.

[20] C. D. Edgar and D. G. Gray, "Induced circular dichroism of chiral nematic cellulose films," Cellulose, vol. 8, no. 1, pp. 5-12, 2001.

[21] Y. P. Zhang, V. P. Chodavarapu, A. G. Kirk, M. P. Andrews, M. Carluer, and G. Picard, "Origin of iridescence in chiral nematic phase nanocrystalline cellulose for encryption and enhanced color," in 6th Emerging Liquid Crystal Technologies, vol. 7955 of Proceedings of SPIE, San Francisco, Calif, USA, January 2011.

[22] S. Ross and I. D. Morrison, Colloidal Systems and Interfaces, John Wiley \& Sons, New York, NY, USA, 1988.

[23] P. Wissling et al., Metallic Effect Pigments, European Coatings Literature, Vincentz Network, Hannover, Germany, 1st edition, 2006. 

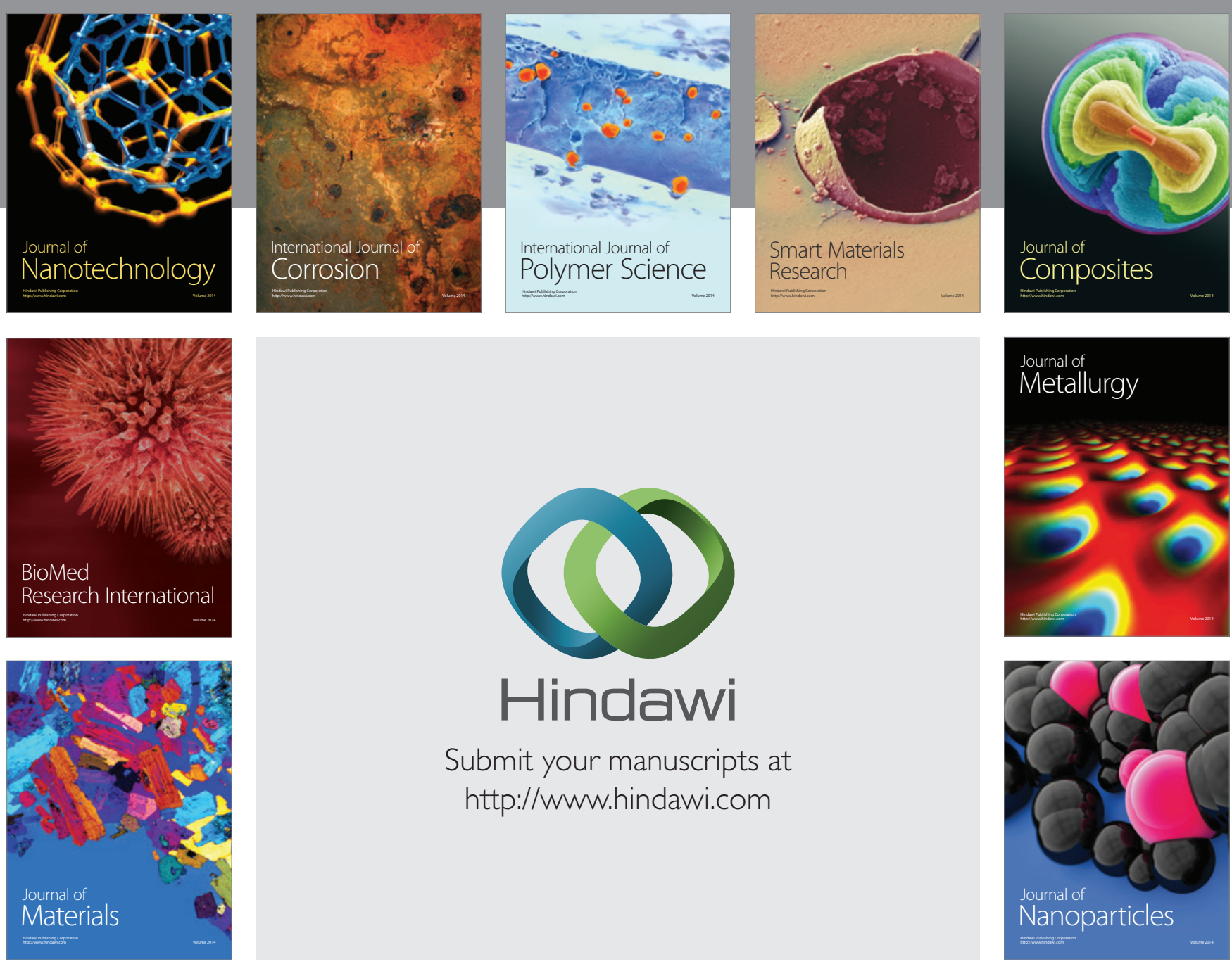

Submit your manuscripts at http://www.hindawi.com
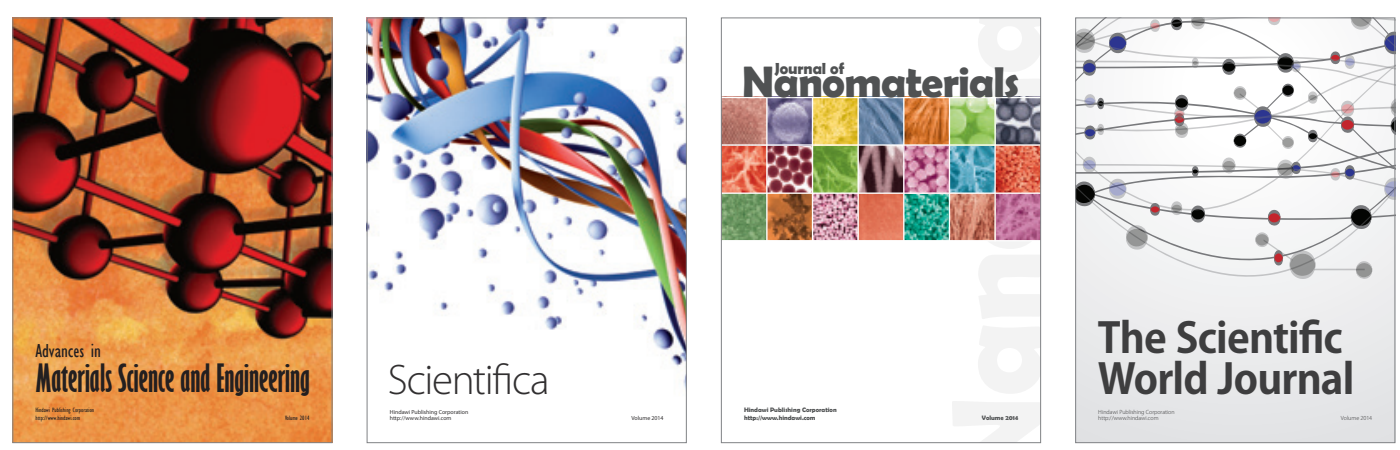

\section{The Scientific World Journal}
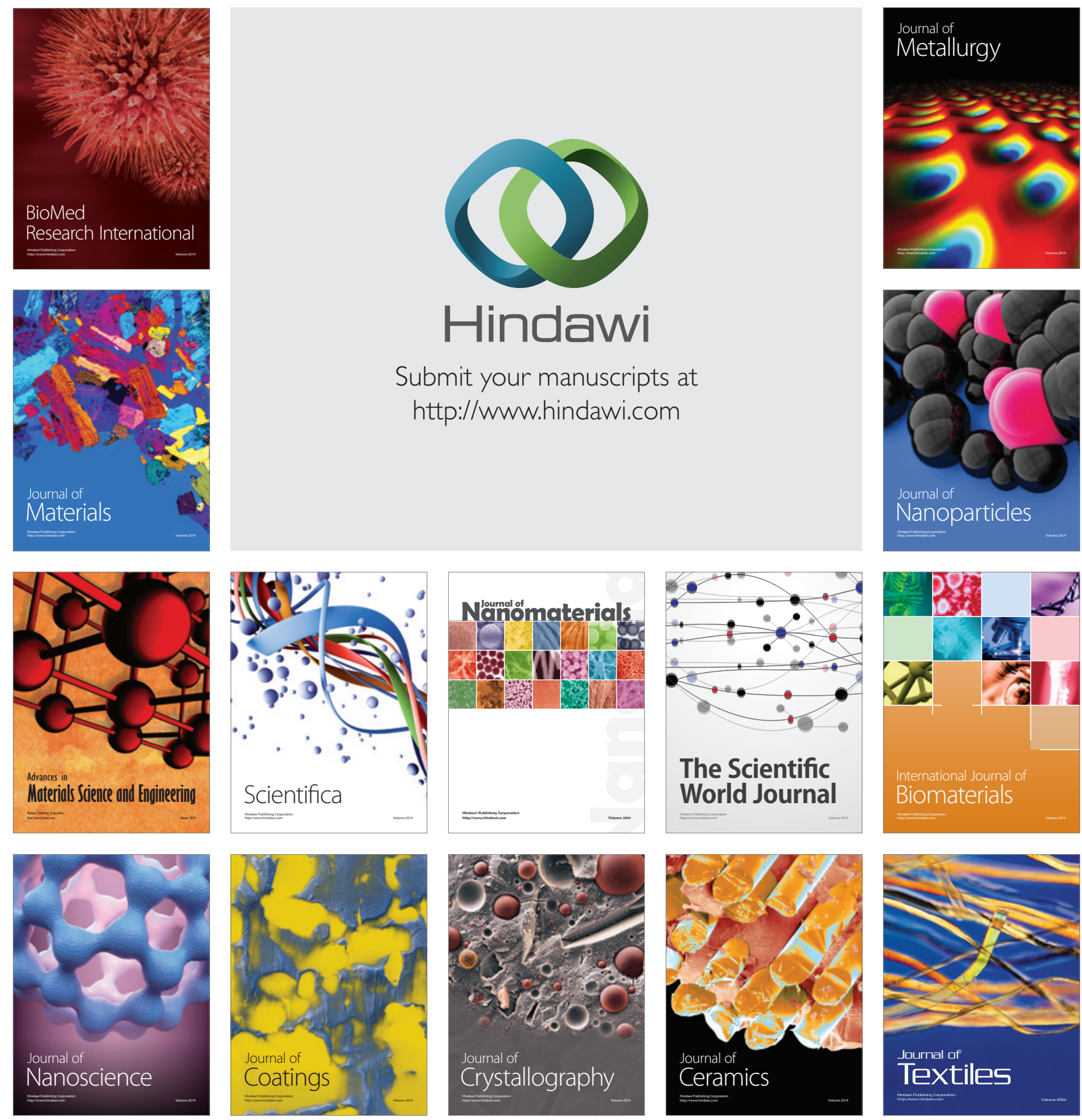